\title{
Adherence to the Mediterranean Diet and Mortality after Breast Cancer
}

\author{
Matteo Di Maso ${ }^{1,2}$, Luigino Dal Maso ${ }^{3}{ }^{-}$, Livia S. A. Augustin ${ }^{4}$, Antonella Puppo ${ }^{5}$, \\ Fabio Falcini ${ }^{6,7}$, Carmen Stocco ${ }^{8}$, Veronica Mattioli ${ }^{3}$, Diego Serraino ${ }^{3}$ DD and Jerry Polesel $^{3, *(D)}$ \\ 1 Department of Clinical Sciences and Community Health, Branch of Medical Statistics, Biometry and \\ Epidemiology G.A. Maccacaro, Università degli Studi di Milano, via A. Vanzetti 5, 20133 Milan, Italy; \\ matteo.dimaso@unimi.it \\ 2 Department of Public Health and Pediatric Sciences, Università degli Studi di Torino, CTO Hospital, \\ via G. Zuretti 29, 10126 Turin, Italy \\ 3 Unit of Cancer Epidemiology, Centro di Riferimento Oncologico di Aviano IRCCS, via Gallini 2, \\ 33081 Aviano, Italy; dalmaso@cro.it (L.D.M.); vmattioli@cro.it (V.M.); serrainod@cro.it (D.S.) \\ 4 Unit of Epidemiology, Istituto Tumori Fondazione Pascale, IRCSS, via M. Semmola 1, 80131 Naples, Italy; \\ l.augustin@istitutotumori.na.it \\ 5 IRCCS Ospedale Policlinico San Martino, Liguria Cancer Registry, Largo R. Benzi 10, 16132 Genova, Italy; \\ antonella.puppo@hsanmartino.it \\ 6 Romagna Cancer Registry, Istituto Scientifico Romagnolo per lo Studio e la Cura dei Tumori (IRST), IRCCS, \\ via P. Maroncelli 40, 47014 Meldola, Italy; fabio.falcini@irst.emr.it \\ 7 Azienda Usl Della Romagna, via della Rocca 19, 47121 Forlì, Italy \\ 8 Veneto Tumour Registry, Azienda Zero, via J. Avanzo 35, 35132 Padova, Italy; carmen.stocco@azero.veneto.it \\ * Correspondence: polesel@cro.it; Tel.: +39-0434-659-195
}

Received: 28 October 2020; Accepted: 25 November 2020; Published: 27 November 2020

\begin{abstract}
Adherence to Mediterranean diet has been consistently associated with a reduced mortality in the general population, but evidence for women with breast cancer is scanty. Methods: A cohort of 1453 women with breast cancer diagnosed between 1991 and 1994 in northern Italy was followed-up for vital status for 15 years after diagnosis. The pre-diagnostic habitual diet was assessed through a structured questionnaire and adherence to the Mediterranean diet was evaluated through the Mediterranean Diet Score. Hazard ratios (HR) of death with confidence intervals (CI) were estimated using Cox model, adjusting for potential confounders. Results: Compared to women who scarcely adhere to the Mediterranean diet $(n=332,22.8 \%)$, those highly adherent $(n=500,34.4 \%)$ reported higher intakes of carbohydrates, mono-unsaturated and poly-unsaturated fatty acids, vitamins, folate, and carotenoids, and lower intakes of cholesterol and animal proteins. Adherence to the Mediterranean diet was associated with a better prognosis: 15 -year overall survival of $63.1 \%$ for high and $53.6 \%$ for low adherence, respectively $(p=0.013)$. HR for all-cause mortality was $0.72(95 \% \mathrm{CI}$ : $0.57-0.92$ ) and HR for breast cancer mortality was 0.65 (95\% CI: $0.43-0.98)$ for women 55 years and older. No significant association emerged for breast cancer mortality in the total cohort. Conclusions: Although dietary habits may have changed after breast cancer diagnosis, these findings indicate that women who ate according to the Mediterranean dietary pattern prior to their diagnosis may have greater chance of a favorable prognosis after breast cancer diagnosis compared to those who did not.
\end{abstract}

Keywords: Mediterranean diet; breast cancer; mortality; survival

\section{Introduction}

Breast cancer $(\mathrm{BrCa})$ is, by far, the most common cancer among women worldwide accounting for over two million cases each year [1]. In Europe, although BrCa still counts as the leading cause of cancer 
death among women [1], the 5-year survival is above $80 \%$ [2]. As a consequence, a considerable number of women are living after a diagnosis of $\mathrm{BrCa}$. For instance, $2.6 \%$ of all Italian women (approximately 0.8 million persons) will be alive in 2020 after a breast cancer diagnosis [3]. The identification of modifiable factors affecting mortality after $\mathrm{BrCa}$ is therefore of great interest.

The association between diet and $\mathrm{BrCa}$ has been extensively investigated considering food groups, single foods, and nutrients [4], including their impact on survival. Favorable oncologic outcomes have been associated to high intakes of fibers [5,6], $\beta$-carotene [5,7], and proteins [8], and to low intake of fats [5,9]. However, findings on individual foods and nutrients provided limited information on the impact of the overall diet on cancer survival, since they do not fully consider the interaction between nutrients. To overcome this problem, dietary patterns have been proposed as a combination of the specific nutritional indicators to evaluate the adherence to healthy diets; these studies reported reduced mortality in BrCa patients following healthy diets (defined according to healthy eating indexes) $[10,11]$, in contrast to Western diet [10].

The Mediterranean diet is unanimously considered a healthy dietary pattern, characterized by high intakes of fruits, vegetables, whole grain products, pulses and fish, and by limited intakes of dairy products and red meat [12]. Adherence to the Mediterranean diet has been consistently associated with a reduced all-cause mortality in the general population, with similar associations across geographic areas [13]; it is therefore of interest to evaluate whether women with BrCa eating according to the Mediterranean diet may benefit from a similar effect on survival. Lower all-cause mortality, but not a cancer-specific one, has been reported among cancer patients adherent to the Mediterranean diet [14]. However, evidence for BrCa is scanty, with only one analysis of the Nurses' Health study [15] suggesting a reduction of approximately $15 \%$ in all-cause mortality, and $20 \%$ in non-BrCa mortality in BrCa patients highly adherent to the Mediterranean diet, compared to those scarcely adherent.

Therefore, the present study aims at investigating the association between adherence to the Mediterranean diet at diagnosis and long-term mortality in a cohort of women with breast cancer living in Italy, an area where the Mediterranean diet is widespread.

\section{Materials and Methods}

This study analyzed data from a retrospective cohort of women with BrCa initially enrolled as cases in an Italian case-control study on the association between lifestyle factors and BrCa risk, whose study design was previously described [16,17]. Study protocol was approved by the Board of Ethics of the participating centers. All patients signed an informed consent at enrollment. Cohort participants were 1453 consecutive patients aged 23-78 years (median age: 55 years) with incident, histologically confirmed BrCa diagnosed during the period 1991-1994 in the major hospitals of the provinces of Pordenone and Forli and the urban area of Genoa in northern Italy. None of them had any prior cancer diagnosis or received previous cancer treatment.

Clinical characteristics at diagnosis, including tumor TNM stage and estrogen/progesterone receptor (ER/PR) status, were gathered from medical records and were centrally reviewed by a clinician. During hospitalization, BrCa patients were interviewed by trained personnel using a structured questionnaire including information on age, education, socio-demographic characteristics, anthropometric measures, lifestyle habits (e.g., drinking and smoking habits, physical activity), personal medical history, and family history of cancer. Body mass index (BMI) was computed as weight $(\mathrm{kg})$ divided by height squared $\left(\mathrm{m}^{2}\right)$.

The habitual diet during the two years prior to cancer diagnosis was assessed through a validated [18] and reproducible [19] food-frequency questionnaire (FFQ). The FFQ included 78 foods, beverages or recipes (i.e., the most common ones in the Italian diet) structured into 7 sections: (i) cereals, bread, and first courses; (ii) second courses (i.e., meat, fish, and other main dishes); (iii) side dishes (i.e., vegetables); (iv) fruits; (v) desserts, sweets, and soft drinks; (vi) hot beverages, milk, and sweeteners; (vii) alcoholic beverages. Patients were asked to indicate the average weekly frequency of consumption of each dietary item. Intakes lower than once a week but at least once a month were 
coded as 0.5 per week. Seasonal consumption was elicited for fruit and vegetables subject to seasonal variation. Daily intakes of food groups were derived from the FFQ by weighting the daily consumption of relevant food items for the corresponding serving weight and summing them up to the food group total. They were expressed in grams per day (g/day). Total energy and nutrient intake were computed using an Italian food composition database [20].

Adherence to Mediterranean diet was investigated using the Mediterranean Diet Score (MDS). This is an a priori score developed using 9 dietary indicators [21], which were high consumption of: cereals, fruit, vegetables, legumes, fish; high monounsaturated/saturated fatty acids (MUFA/SFA) ratio; low consumption of: dairy products (including milk) and meat; and moderate alcohol consumption. For each food group and nutrient, high or low consumption was defined according to its median value; for alcohol intake, moderate alcohol consumption was defined as 1-3 drinks/day. For each study participant and each diet indicator, a value of 1 was assigned when the subject fulfilled the MDS requirement, 0 otherwise. The MDS was calculated adding up the values for each of the 9 components; thus, the score ranged from 0 (representing minimal adherence) to 9 (maximal adherence). According to MDS, adherence to Mediterranean diet was classified as low (MDS: 0-3), moderate (MDS: 4-5), or high (MDS: 6-9).

The vital status, the date of death, and the underlying cause of death were ascertained through a record-linkage procedure with the population-based regional cancer registries covering the areas where patients were enrolled [17]. Person-time at risk was computed from the date of BrCa diagnosis to the date of death or to the end of follow-up, whichever came first. Median length of follow-up was 12.6 years (maximum: 16.8 years). The follow-up for the present analysis was truncated at 15 years after diagnosis.

The overall survival probabilities according to MDS were estimated by means of the Kaplan-Meier method and survival differences were tested through the log-rank test [22]. To account for competing risks, cause-specific mortality was evaluated through cumulative incidence [23], and differences according to MDS were tested through Gray's test [24]. Hazard ratios (HRs) of death for all-causes and corresponding 95\% confidence intervals (CIs) were estimated using Cox Proportional Hazards model [22], after checking for the proportional hazards assumption through the inspection of Schoenfeld residuals and including interactions with follow-up time [22]. HRs were adjusted for study design variables (area of residence, calendar period of cancer diagnosis), socio-demographic characteristics (age at diagnosis, education, menopausal status), clinical cancer features (TNM stage, ER/PR status), and total energy intake. Kruskal-Wallis test was used to test differences in food groups or nutrient intake according to levels of adherence to the Mediterranean diet. Statistical significance was claimed for $p<0.05$ (two-tailed).

\section{Results}

At BrCa diagnosis, 500 (34.4\%) patients reported high adherence to Mediterranean diet (MDS =6-9) whereas $332(22.8 \%)$ reported low adherence (MDS = 0-3; Table 1). Adherence to Mediterranean diet was significantly higher in patients younger than 45 years than those aged $\geq 45$ years $(p=0.028)$, and in current drinkers than in never drinkers $(p<0.001$; Table 1$)$. 
Table 1. Distribution of 1453 women diagnosed with breast cancer, according to baseline socio-demographic and clinical characteristics and Mediterranean Diet Score (MDS).

\begin{tabular}{|c|c|c|c|c|c|c|c|}
\hline & \multicolumn{6}{|c|}{ Adherence to Mediterranean Diet (MDS) } & \\
\hline & \multicolumn{2}{|c|}{ Low (0-3) } & \multicolumn{2}{|c|}{ Moderate (4-5) } & \multicolumn{2}{|c|}{ High (6-9) } & \\
\hline & $n$ & $(\%)$ & $n$ & $(\%)$ & $n$ & $(\%)$ & \\
\hline All patients & 332 & $(22.8)$ & 621 & $(42.7)$ & 500 & $(34.4)$ & \\
\hline \multicolumn{8}{|c|}{ Age at diagnosis (years) } \\
\hline$<45$ & 53 & $(20.4)$ & 109 & $(41.9)$ & 98 & $(37.7)$ & \\
\hline $45-54$ & 108 & $(25.1)$ & 168 & $(39.1)$ & 154 & $(35.8)$ & \\
\hline $55-64$ & 95 & $(21.1)$ & 191 & $(42.4)$ & 165 & $(36.6)$ & \\
\hline$\geq 65$ & 76 & $(24.4)$ & 153 & $(49.0)$ & 83 & $(26.6)$ & $p=0.028$ \\
\hline \multicolumn{8}{|c|}{ Education (yrs) ${ }^{1}$} \\
\hline$<7$ & 186 & $(25.3)$ & 318 & $(43.3)$ & 230 & $(31.3)$ & \\
\hline $7-11$ & 92 & $(22.1)$ & 168 & $(40.4)$ & 156 & $(37.5)$ & \\
\hline$\geq 12$ & 52 & $(17.5)$ & 134 & $(45.0)$ & 112 & $(37.6)$ & $p=0.058$ \\
\hline \multicolumn{8}{|c|}{ Menopausal status } \\
\hline Pre/Peri & 121 & $(21.8)$ & 237 & $(42.9)$ & 195 & $(35.3)$ & \\
\hline Post & 211 & $(23.4)$ & 384 & $(42.7)$ & 305 & $(33.9)$ & $p=0.757$ \\
\hline \multicolumn{8}{|c|}{ Current tobacco smoking } \\
\hline No & 255 & $(21.9)$ & 509 & $(43.8)$ & 399 & $(34.3)$ & \\
\hline Yes & 77 & $(26.6)$ & 112 & $(38.6)$ & 101 & $(34.8)$ & $p=0.163$ \\
\hline \multicolumn{8}{|c|}{ BMI $\left(\mathrm{kg} \mathrm{m}^{-2}\right)^{1}$} \\
\hline$<25$ & 178 & $(21.9)$ & 342 & $(42.0)$ & 296 & $(36.1)$ & \\
\hline 25-29.9 & 110 & $(23.7)$ & 199 & $(42.9)$ & 155 & $(33.4)$ & \\
\hline$\geq 30$ & 44 & $(25.6)$ & 78 & $(45.4)$ & 50 & $(29.1)$ & $p=0.574$ \\
\hline \multicolumn{8}{|l|}{ TNM stage } \\
\hline I & 106 & $(22.3)$ & 190 & $(40.0)$ & 179 & $(37.7)$ & \\
\hline II & 141 & $(22.0)$ & 287 & $(44.7)$ & 214 & $(33.3)$ & \\
\hline III-IV & 45 & $(23.3)$ & 80 & $(41.5)$ & 68 & $(35.2)$ & \\
\hline Unknown & 40 & $(28.0)$ & 64 & $(44.8)$ & 39 & $(27.3)$ & $p=0.284$ \\
\hline \multicolumn{8}{|l|}{ ER/PR status } \\
\hline $\mathrm{ER}^{+} / \mathrm{PR}^{+}$ & 46 & $(31.3)$ & 58 & $(39.5)$ & 43 & $(29.3)$ & \\
\hline $\mathrm{ER}^{-} / \mathrm{PR}^{+}$ & 12 & $(23.1)$ & 18 & $(34.6)$ & 22 & $(42.3)$ & \\
\hline $\mathrm{ER}^{+} / \mathrm{PR}^{-}$ & 20 & $(21.7)$ & 39 & $(42.4)$ & 33 & (35.9) & \\
\hline $\mathrm{ER}^{-} / \mathrm{PR}^{-}$ & 136 & $(22.6)$ & 267 & $(44.3)$ & 200 & $(33.2)$ & \\
\hline Unknown & 118 & $(21.1)$ & 239 & $(42.8)$ & 202 & $(36.1)$ & $p=0.279$ \\
\hline
\end{tabular}

BMI: body mass index; ER: estrogen receptor $\left({ }^{-}\right.$: Negative; ${ }^{+}$: Positive); PR: progesterone receptor. ${ }^{1}$ The sum does not add up to total because of missing values.

Women highly adherent to the Mediterranean diet reported higher intakes of cereals, fish, fruit, vegetables and legumes, and a lower intake of dairy products (Table 2). In patients highly adherent to the Mediterranean diet, fats and proteins from vegetable sources were preferred to those from animal sources (Table 3). Further, intake of carbohydrates, mono-unsaturated fatty acids, poly-unsaturated fatty acids, vitamins, folate, and carotenoids significantly increased with increasing adherence to Mediterranean diet, whereas cholesterol intake showed an opposite trend. 
Table 2. Median intake of food groups and interquartile range (Q1-Q3) according to adherence to Mediterranean diet.

\begin{tabular}{|c|c|c|c|c|c|c|c|}
\hline Food Group & \multicolumn{2}{|c|}{ Low Adherence } & \multicolumn{2}{|c|}{ Moderate Adherence } & \multicolumn{2}{|c|}{ High Adherence } & Kruskal-Wallis Test \\
\hline Cereals (g) & 152 & $(119-188)$ & 172 & $(132-220)$ & 200 & $(159-253)$ & $p<0.001$ \\
\hline Red/processed meat (g) & 96 & $(67-125)$ & 96 & $(66-128)$ & 91 & $(63-124)$ & $p=0.343$ \\
\hline Fish (g) & 21 & $(11-27)$ & 27 & $(16-43)$ & 33 & $(27-49)$ & $p<0.001$ \\
\hline Vegetables (g) & 289 & $(189-361)$ & 366 & $(241-521)$ & 458 & $(343-590)$ & $p<0.001$ \\
\hline Legumes (g) & 23 & $(14-32)$ & 32 & $(18-50)$ & 46 & $(32-68)$ & $p<0.001$ \\
\hline Desserts (g) & 43 & $(17-78)$ & 40 & $(18-74)$ & 38 & $(18-71)$ & $p=0.745$ \\
\hline
\end{tabular}

Table 3. Nutrient median values and interquartile range (Q1-Q3) according to adherence to Mediterranean diet.

\begin{tabular}{|c|c|c|c|c|c|c|c|}
\hline \multirow{2}{*}{$\begin{array}{l}\text { Daily Nutrient } \\
\text { Intake }\end{array}$} & \multicolumn{2}{|c|}{ Low Adherence } & \multicolumn{2}{|c|}{ Moderate Adherence } & \multicolumn{2}{|c|}{ High Adherence } & \multirow{2}{*}{$\begin{array}{c}\text { Kruskal-Wallis } \\
\text { Test }\end{array}$} \\
\hline & Med & (Q1-Q3) & Med & (Q1-Q3) & Med & (Q1-Q3) & \\
\hline Total proteins $(\mathrm{g})$ & 85.5 & $(72.0-99.2)$ & 87.5 & $(74.4-104.3)$ & 89.9 & $(74.9-105.5)$ & $p=0.017$ \\
\hline Vegetable proteins $(\mathrm{g})$ & 25.6 & $(20.6-30.2)$ & 29.1 & $(24.7-34.9)$ & 33.3 & $(27.8-39.4)$ & $p<0.001$ \\
\hline Animal proteins $(\mathrm{g})$ & 59.8 & $(48.9-71.4)$ & 58.0 & $(47.4-70.8)$ & 56.2 & $(44.4-68.2)$ & $p=0.005$ \\
\hline Total fats (g) & 75.6 & $(62.5-94.6)$ & 80.9 & $(65.0-100.3)$ & 88.3 & $(71.1-108.6)$ & $p<0.001$ \\
\hline Vegetable fats (g) & 31.0 & $(23.3-41.7)$ & 37.0 & $(27.9-48.6)$ & 47.7 & $(35.4-60.9)$ & $p<0.001$ \\
\hline Animal fats (g) & 44.7 & $(34.2-55.7)$ & 42.4 & $(32.9-53.5)$ & 39.4 & $(30.7-50.3)$ & $p<0.001$ \\
\hline Carbohydrates (g) & 242.4 & $(193.9-292.3)$ & 268.8 & $(225.1-322.7)$ & 292.3 & $(245.4-352.0)$ & $p<0.001$ \\
\hline Sugars $(g)$ & 90.8 & $(68.4-115.6)$ & 100.7 & $(77.8-126.7)$ & 107.4 & $(86.4-134.8)$ & $p<0.001$ \\
\hline Starch $(g)$ & 147.8 & $(117.3-185.2)$ & 161.0 & $(129.9-204.8)$ & 185.6 & $(149.8-224.4)$ & $p<0.001$ \\
\hline Fiber $(\mathrm{g})$ & 19.4 & $(15.5-23.3)$ & 23.4 & $(19.6-28.2)$ & 27.5 & $(23.5-32.5)$ & $p<0.001$ \\
\hline SAFA (g) & 27.5 & $(21.6-34.3)$ & 27.7 & $(21.5-34.2)$ & 27.5 & $(21.3-34.5)$ & $p=0.908$ \\
\hline MUFA (g) & 32.2 & $(24.8-40.7)$ & 35.3 & $(27.4-45.0)$ & 42.6 & $(32.3-54.0)$ & $p<0.001$ \\
\hline PUFA (g) & 10.9 & $(8.2-14.6)$ & 11.3 & $(8.5-16.1)$ & 12.1 & $(9.6-15.6)$ & $p=0.001$ \\
\hline Cholesterol (mg) & 316.6 & $(251.8-403.6)$ & 320.1 & $(254.3-405.9)$ & 304.6 & $(236.6-379.2)$ & $p=0.049$ \\
\hline Calcium (g) & 1.06 & $(0.82-1.30)$ & 0.99 & $(0.77-1.29)$ & 0.96 & $(0.75-1.23)$ & $p=0.033$ \\
\hline Potassium (g) & 3.37 & $(2.77-4.06)$ & 3.74 & $(3.19-4.37)$ & 4.07 & $(3.51-4.69)$ & $p<0.001$ \\
\hline Iron (mg) & 12.6 & $(10.3-14.8)$ & 13.6 & $(11.5-16.2)$ & 14.8 & $(12.6-17.6)$ & $p<0.001$ \\
\hline Thiamin (mg) & 0.80 & $(0.64-0.95)$ & 0.85 & $(0.71-0.99)$ & 0.91 & $(0.76-1.07)$ & $p<0.001$ \\
\hline Riboflavin (mg) & 1.50 & $(1.26-1.91)$ & 1.52 & $(1.21-1.88)$ & 1.52 & $(1.26-1.85)$ & $p=0.985$ \\
\hline Vitamin C (mg) & 114.9 & (81.3-148.8) & 142.1 & (100.1-190.2) & 165.8 & (127.8-215.8) & $p<0.001$ \\
\hline Vitamin B6 (mg) & 1.70 & $(1.39-2.01)$ & 1.86 & $(1.56-2.19)$ & 1.97 & $(1.68-2.29)$ & $p<0.001$ \\
\hline Folate $(\mu \mathrm{g})$ & 231.1 & $(190.9-275.4)$ & 267.5 & $(218.4-311.8)$ & 293.5 & $(251.3-346.7)$ & $p<0.001$ \\
\hline Niacin (mg) & 15.6 & $(12.7-18.2)$ & 16.9 & $(14.2-19.9)$ & 18.4 & $(15.5-21.1)$ & $p<0.001$ \\
\hline$\alpha$-Carotene $(\mu \mathrm{g})$ & 449.5 & $(185.7-786.8)$ & 587.1 & $(308.1-957.6)$ & 792.3 & $(479.7-1237)$ & $p<0.001$ \\
\hline$\beta$-Carotene (mg) & 3.91 & $(2.95-5.02)$ & 4.88 & $(3.69-6.11)$ & 5.88 & $(4.68-7.26)$ & $p<0.001$ \\
\hline Vitamin D $(\mu \mathrm{g})$ & 2.43 & $(1.86-3.15)$ & 2.85 & $(2.13-3.62)$ & 3.23 & $(2.53-4.17)$ & $p<0.001$ \\
\hline Vitamin E (mg) & 11.7 & $(9.30-15.0)$ & 13.9 & (11.2-17.1) & 16.8 & $(13.5-20.1)$ & $p<0.001$ \\
\hline Total energy (kJ) & 8473 & (7213-10339) & 9192 & $(7849-10841)$ & 9937 & $(8372-11673)$ & $p<0.001$ \\
\hline
\end{tabular}

Med: Median value.

During the 15-year follow-up, 503 patients (34.6\%) had died with a median time to death of 64 months. Overall, $365(72.6 \%)$ were attributed to $\mathrm{BrCa}$ and $138(27.4 \%)$ to other causes. BrCa patients highly adherent to Mediterranean diet reported a higher survival than those with low adherence $(p=0.013)$ : the 15 -year survival probability was $63.1 \%$ and $53.6 \%$ for high and low adherence, respectively (Figure 1). The advantage in overall survival in women with high MDS compared to low MDS was confirmed by multivariate analysis (Table 4), with HR for death of 0.72 (95\% CI: 0.57-0.92). 


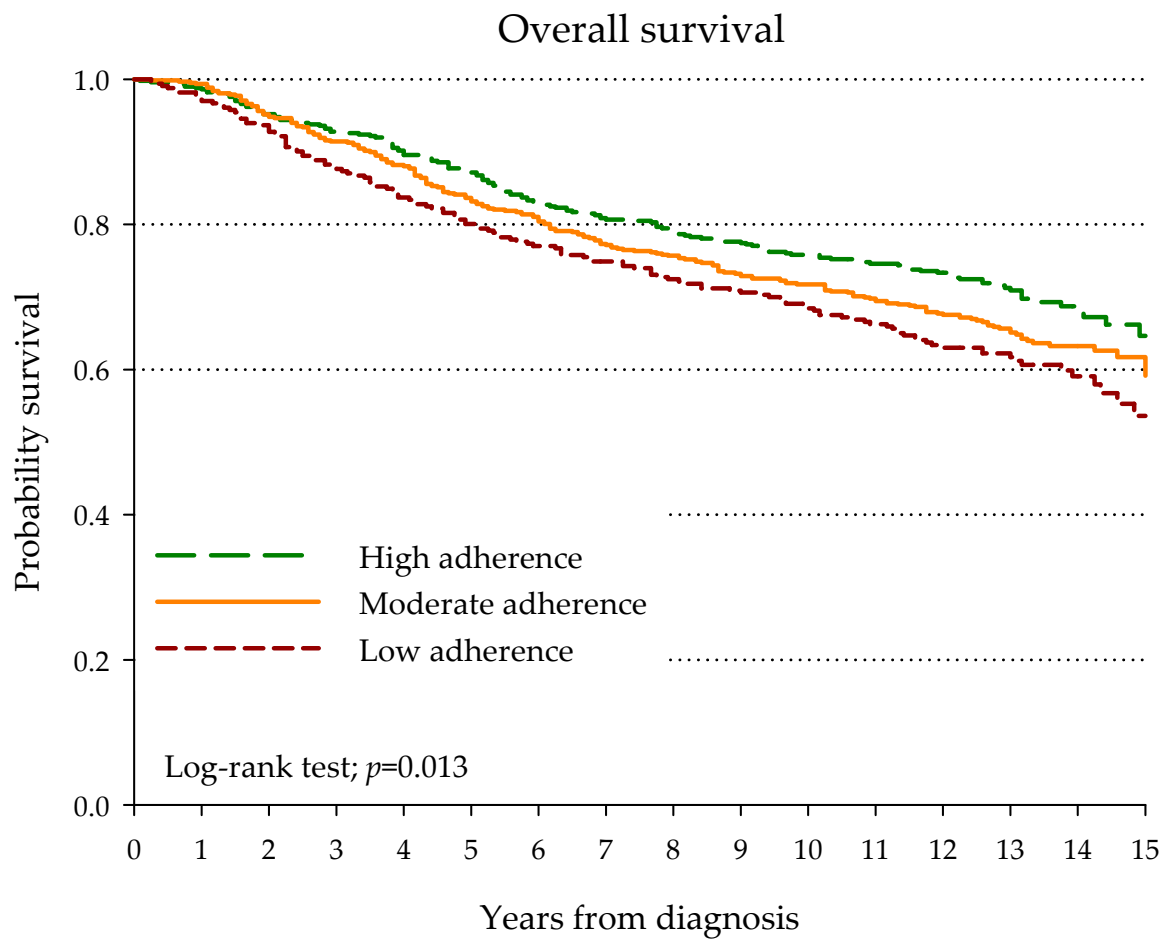

Figure 1. Kaplan-Meier estimates of overall survival according to adherence to the Mediterranean diet.

Table 4. Hazard ratios (HR) of death and corresponding 95\% confidence intervals (CI) by adherence to the Mediterranean diet.

\begin{tabular}{|c|c|c|c|c|}
\hline \multirow{2}{*}{ Adherence to Mediterranean Diet } & \multirow{2}{*}{ Patients } & \multicolumn{2}{|c|}{ Deaths } & \multirow{2}{*}{$\operatorname{HR}(95 \% \mathrm{CI})^{1}$} \\
\hline & & $n$ & $(\%)$ & \\
\hline \multicolumn{5}{|c|}{ All-cause mortality } \\
\hline Low & 332 & 132 & $(43.8)$ & Reference \\
\hline Moderate & 621 & 220 & $(35.4)$ & $0.86(0.69-1.07)$ \\
\hline High & 500 & 151 & $(30.2)$ & $0.72(0.57-0.92)$ \\
\hline \multicolumn{5}{|c|}{ Breast cancer mortality } \\
\hline Low & 332 & 93 & $(28.0)$ & Reference \\
\hline Moderate & 621 & 154 & $(24.8)$ & $0.88(0.67-1.15)$ \\
\hline High & 500 & 118 & $(23.6)$ & $0.83(0.62-1.11)$ \\
\hline \multicolumn{5}{|c|}{ Non-breast cancer mortality } \\
\hline Low & 332 & 41 & $(12.1)$ & Reference \\
\hline Moderate & 621 & 63 & $(10.3)$ & $0.87(0.58-1.29)$ \\
\hline High & 500 & 34 & $(6.8)$ & $0.58(0.36-0.93)$ \\
\hline
\end{tabular}

\footnotetext{
1 Estimated using Cox proportional hazard model adjusted for area of residence at diagnosis, calendar period of cancer diagnosis, age at diagnosis, years of education, menopausal status, TNM stage, estrogen/progesterone receptor status, and total energy intake. Cause-specific mortality was further adjusted for competing risk according to Fine-Gray model.
}

Adherence to Mediterranean diet was not significantly associated to BrCa-specific mortality $(p=0.396$, Figure 2), although the cumulative incidence of BrCa-related deaths was higher among women with low adherence. Non-BrCa-specific mortality was significantly lower among women highly adherent to Mediterranean diet $(p=0.033)$. These findings were confirmed by the multivariate model (Table 4), where high adherence to the Mediterranean diet was significantly associated with reduced non-BrCa-related mortality alone $(\mathrm{HR}=0.58 ; 95 \% 0.36-0.93)$. 

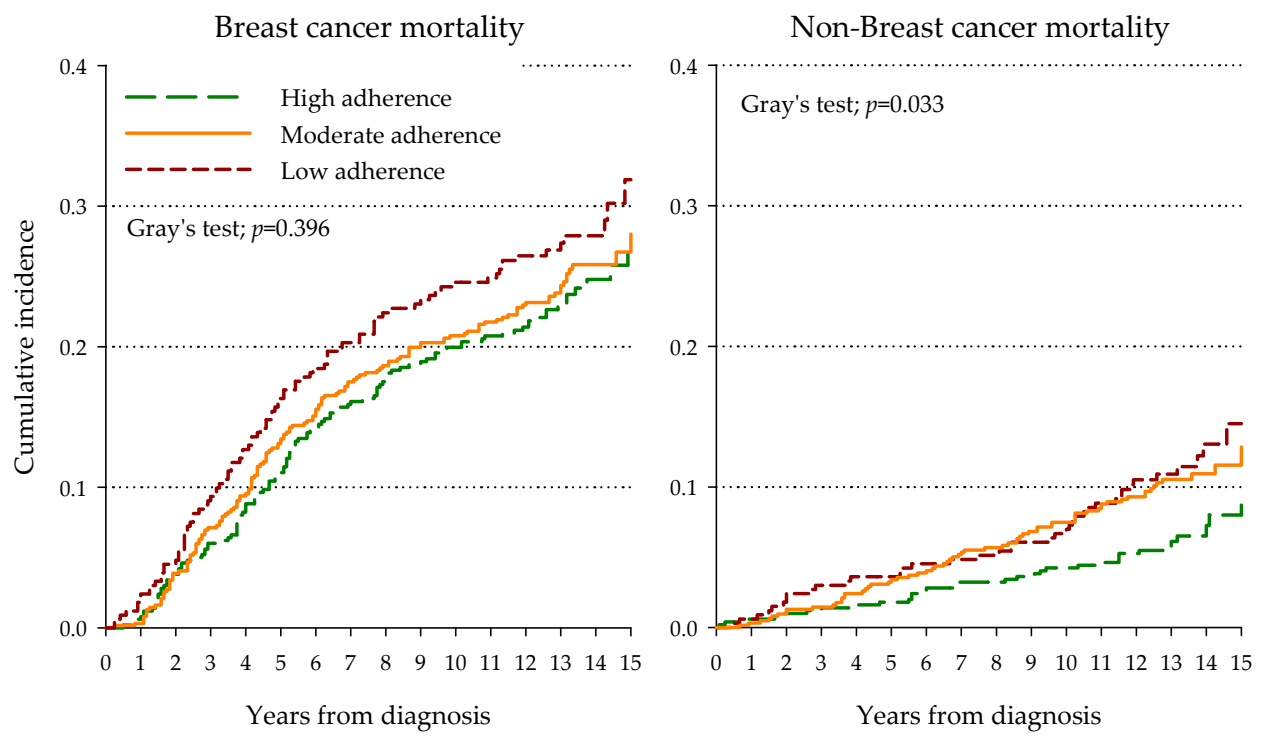

Figure 2. Kaplan-Meier estimates of cumulative incidence of breast cancer and non-breast cancer mortality according to adherence to Mediterranean diet.

The association between Mediterranean diet and mortality was further investigated according to strata of age, menopausal status, and BMI (Table 5). No significant associations emerged in women diagnosed at age $<55$ years. Conversely, in those aged $\geq 55$ years, high adherence to Mediterranean diet was significantly inversely associated with overall mortality ( $\mathrm{HR}=0.55 ; 95 \% \mathrm{CI}: 0.39-0.76)$, as well as BrCa mortality ( $\mathrm{HR}=0.65 ; 95 \% \mathrm{CI}$ : $0.43-0.98)$ and non-BrCa mortality ( $\mathrm{HR}=0.51 ; 95 \% \mathrm{CI}$ : 0.30-0.90). A similar pattern emerged for menopausal status: a significant inverse association between adherence to the Mediterranean diet and mortality emerged only among postmenopausal women, though the effect on $\mathrm{BrCa}$ mortality in post-menopausal women was not statistically significant. Further, the inverse association between adherence to the Mediterranean diet and mortality was more evident in overweight/obese patients than in those with normal weight. Indeed, among patients with BMI $\geq 25 \mathrm{~kg} \mathrm{~m}^{-2}$, the risk of all-cause death was 0.70 (95\% CI: 0.51-0.96) in patients moderately adherent to the Mediterranean diet and 0.64 (95\% CI: 0.45-0.92) in those highly adherent. No such associations emerged in women with BMI $<25 \mathrm{~kg} \mathrm{~m}^{-2}$.

Table 5. Hazard ratios (HR) ${ }^{1}$ of death and corresponding $95 \%$ confidence intervals (CI) by adherence to the Mediterranean diet according to selected strata.

\begin{tabular}{|c|c|c|c|c|c|c|}
\hline & \multicolumn{2}{|c|}{ Age (Years) } & \multicolumn{2}{|c|}{ Menopausal Status } & \multicolumn{2}{|c|}{ BMI (kg m $\left.{ }^{-2}\right)$} \\
\hline & $<55$ & $\geq 55$ & Pre/Peri & Post & $<25$ & $\geq 25$ \\
\hline \multicolumn{7}{|c|}{ All-cause mortality } \\
\hline Low & Reference & Reference & Reference & Reference & Reference & Reference \\
\hline Moderate & $1.04(0.72-1.51)$ & $0.76(0.58-1.00)$ & $1.06(0.69-1.62)$ & $0.79(0.61-1.02)$ & $0.97(0.71-1.33)$ & $0.70(0.51-0.96)$ \\
\hline High & $1.01(0.69-1.48)$ & $0.55(0.39-0.76)$ & $1.01(0.65-1.58)$ & $0.65(0.48-0.87)$ & $0.81(0.58-1.14)$ & $0.64(0.45-0.92)$ \\
\hline \multicolumn{7}{|c|}{ Breast cancer mortality } \\
\hline Low & Referenc & Refer & Reference & Refe & Refe & $\operatorname{Ref}$ \\
\hline Moderate & $1.03(0.69-1.56)$ & $0.78(0.54-1.12)$ & $1.04(0.65-1.69)$ & $0.80(0$ & $1.14(0.77-1.69)$ & $0.65(0.4$ \\
\hline High & $1.06(0.69-1.61)$ & $0.65(0.43-0.98)$ & $1.06(0.65-1.71)$ & $0.73(0.51-1.05)$ & $0.97(0.64-1.46)$ & $0.73(0.48-1.11)$ \\
\hline \multicolumn{7}{|c|}{ Non-breast cancer mortality } \\
\hline Low & Reference & Reference & Reference & Refere & Reference & Reference \\
\hline Moderate & $0.88(0.34-2.33)$ & $0.86(0.55-1.34)$ & $0.84(0.28-2.51)$ & $0.88(0.55-1.31)$ & $0.68(0.39-1.16)$ & $0.99(0.54-1.81)$ \\
\hline High & $0.67(0.27-1.82)$ & $0.51(0.30-0.90)$ & $0.67(0.24-1.87)$ & $0.58(0.34-0.99)$ & $0.62(0.33-1.15)$ & $0.51(0.24-1.08)$ \\
\hline
\end{tabular}

\footnotetext{
${ }^{1}$ Estimated using Cox Proportional Hazard Model adjusted for area of residence at diagnosis, calendar period of cancer diagnosis, age at diagnosis, years of education, TNM stage, estrogen/progesterone receptor status, and total energy intake, when appropriate.
} 


\section{Discussion}

The results of the present study support a beneficial role of prediagnostic Mediterranean diet in survival in women with $\mathrm{BrCa}$, with reductions in the risk of all-cause and non-BrCa-associated deaths. The beneficial effect of the high adherence to the Mediterranean diet is particularly evident in women 55 years and older who also showed a reduced risk of BrCa-specific death.

Adherence to the Mediterranean diet has been associated with reduced incidence of several health outcomes [25], including overall mortality and cancer-specific mortality [13,25]. Nonetheless, very few studies have been conducted on survival in cancer patients $[15,26,27]$. In particular, only one previous analysis in post-menopausal women focused on breast cancer [15]: in comparison to women scarcely adherent to the Mediterranean diet, those who were highly adherent reported a $26 \%$ reduction in all-cause mortality and a $42 \%$ reduction in non-BrCa-specific mortality. However, these associations were no longer significant when lifestyle and clinical variables were included as covariates.

The favorable effect of the Mediterranean diet on mortality and other health outcomes has been usually attributed to the additive health benefits of each nutrient that characterize this diet [13]. High fiber intake has been associated with a reduction in both all-cause and BrCa-specific mortality, with a strong linear relationship [6]. Similarly, elevated dietary intake of $\beta$-carotene, a marker of vegetable and fruit intake, has been associated with a 30\% decrease in overall mortality [7]. Furthermore, lower dietary fat intake, especially from animal origin, has been associated with improved survival after $\mathrm{BrCa}[5,9]$. These findings are in line with the results of the present study; although we did not evaluate the association between single components of the Mediterranean diet and mortality, women highly adherent to the Mediterranean diet reported higher daily intakes of fiber, vegetable fats and carotenoids, and lower intakes of animal fats than women scarcely adherent. Several studies reported an advantage in overall survival and progression-free survival with increased protein intake [8]. In the present study, total protein intake, particularly from vegetable sources, increased with increasing adherence to the Mediterranean diet. However, it is worth noting that the increase in total protein in our study was mainly due to those from vegetable sources, whereas those from animal sources declined with increasing MDS.

In this study, adherence to the Mediterranean diet did not modify the survival in women younger than 55 years at diagnosis. Conversely, among women older than 55 years, high adherence to the Mediterranean diet reduced both $\mathrm{BrCa}$ and non-BrCa mortality. Similarly, no effect of Mediterranean diet emerged for pre-menopausal $\mathrm{BrCa}$. Young women are affected more frequently by aggressive $\mathrm{BrCa}$ molecular subtypes [28], in particular by triple-negative $\mathrm{BrCa}$, which is associated with poor prognosis and early death [28]. Therefore, it is likely that the prognosis of these patients is scarcely affected by lifestyle factors [9]. This could partly explain the lack of association between the Mediterranean diet and $\mathrm{BrCa}$ outcomes in patients younger than 55 years. Indeed, although triple-negative BrCa could not be identified in our study due to the lack of information on human epidermal growth factor receptor 2 status, the prevalence of $\mathrm{ER}^{-} / \mathrm{PR}^{-}$was higher among women aged $<55$ years at diagnosis than among older ones (i.e., $45.8 \%$ and $37.6 \%$, respectively).

In the present study, the beneficial effect of the Mediterranean diet on BrCa prognosis was more evident among patients with BMI $\geq 25 \mathrm{~kg} \mathrm{~m}^{-2}$. A worse prognosis in overweight and obese women has already been reported in the present study population [17]. It is therefore possible that the beneficial effect of the Mediterranean diet emerged more where the baseline risk of death was higher, through the reduction of other comorbidities that impact survival. Clinical and observational studies have consistently reported inverse associations between adherence to the Mediterranean diet and risk of metabolic syndrome [29]. Besides the overweight factor and obesity, the Mediterranean diet has been associated with each medical condition defining the metabolic syndrome, such as hypercholesterolemia, hypertension, hypertriglyceridemia and hyperglycemia [29]. Furthermore, epigenetic modifications due to the Mediterranean diet has recently been reported in an interventional study conducted on overweight BrCa patients [30] which showed significant changes in the expression of 42 extracellular miRNAs after an 8-week Mediterranean dietary treatment. Genetic pathways regulated 
by the differentially expressed miRNAs include signaling associated with $\mathrm{BrCa}$, energy metabolism, glucose metabolism, and insulin [30].

The lack of information on modifications of dietary habits after $\mathrm{BrCa}$ diagnosis was a major limitation in our current study. Although an increase in vegetable and fruit consumption after diagnosis has been reported in French women [31], this was unlikely to have occurred in Italian women diagnosed with BrCa between 1991 and 1994 since, at that time, the general population had not been made aware of any putative association between diet and cancer survival, and no dietary guidelines existed for patients with BrCa. Furthermore, studies investigating dietary modification in relation to $\mathrm{BrCa}$ survival consistently reported similar results when adherence to healthy diets was measured before and after $\mathrm{BrCa}$ [10]. The lack of information on type of treatment after $\mathrm{BrCa}$ diagnosis may be another study weakness. Selection bias may also have occurred. However, study patients were women previously enrolled as cases in a hospital-based case-control study [16] recruiting all newly diagnosed BrCa patients consecutively admitted to the major local hospitals in the study areas; no selection for specific clinical characteristics or treatments was done and refusal rate and loss to follow-up was below $5 \%$. Thus, the present study population could be considered representative of BrCa patients in the study areas.

\section{Conclusions}

The findings of the present study further support the beneficial impact of the Mediterranean on BrCa outcomes, in particular in those overweight or obese and in older women. Although results might be biased by the lack of postdiagnosis dietary information, these results indicate that women who ate according to the Mediterranean diet prior to $\mathrm{BrCa}$ diagnosis had a higher chance of a favorable prognosis. Thus, in agreement with current cancer prevention guidelines [32], this study encourages women to follow a healthy diet. In summary, the Mediterranean diet, which has been associated with longevity in otherwise healthy subjects may also prolong life in women with a BrCa diagnosis.

Author Contributions: Conceptualization, J.P., L.D.M. and L.S.A.A.; methodology, J.P. and L.D.M.; formal analysis, M.D.M. and V.M.; data curation, A.P., F.F., C.S. and D.S.; writing-original draft preparation, J.P. and L.S.A.A.; writing-review and editing, M.D.M., L.D.M., A.P, F.F., C.S. and D.S.; supervision, D.S.; funding acquisition, L.D.M. All authors have read and agreed to the published version of the manuscript.

Funding: This research was partially funded by the Italian Association for Research on Cancer (AIRC IG No. 1468) and by Italian Ministry of Health (Ricerca Corrente) (no grant number provided).

Acknowledgments: The authors wish to thank Luigina Mei, Unit of Cancer Epidemiology, Centro di Riferimento Oncologico di Aviano (CRO) IRCCS, for editorial assistance. The study was conducted within the Prospective Analysis of Case-control studies on Environmental factors and health (PACE) study group: Silvia Franceschi, Renato Talamini, Federica Toffolutti (Unit of Cancer Epidemiology, Centro di Riferimento Oncologico di Aviano IRCCS, Aviano (PN), Italy); Maria Parpinel (Università degli Studi di Udine, via Colugna 50, 33100 Udine (UD), Italy); Claudia Casella, Rosa Angela Filiberti (IRCCS Ospedale Policlinico San Martino, Liguria Cancer Registry, Genova (GE), Italy); Alessandra Ravaioli (Romagna Cancer Registry, Istituto Scientifico Romagnolo per lo Studio e la Cura dei Tumori (IRST), IRCCS, Meldola (TC), Italy; Azienda Usl della Romagna, Forlì (FC), Italy).

Conflicts of Interest: L.S.A. has received honoraria from the Nutrition Foundation of Italy (NFI) to co-organize the International Carbohydrate Quality Consortium (ICQC) meetings. The remaining authors declare no conflict of interest. The funders had no role in the design of the study; in the collection, analyses, or interpretation of data; in the writing of the manuscript, or in the decision to publish the results.

\section{References}

1. Ferlay, J.; Colombet, M.; Soerjomataram, I.; Mathers, C.; Parkin, D.M.; Piñeros, M.; Znaor, A.; Bray, F. Estimating the global cancer incidence and mortality in 2018: GLOBOCAN sources and methods. Int. J. Cancer 2019, 144, 1941-1953. [CrossRef] [PubMed]

2. Sant, M.; Chirlaque Lopez, M.D.; Agresti, R.; Sánchez Pérez, M.J.; Holleczek, B.; Bielska-Lasota, M.; Dimitrova, N.; Innos, K.; Katalinic, A.; Langseth, H.; et al. Survival of women with cancers of breast and genital organs in Europe 1999-2007: Results from the EUROCARE-5 study. Eur. J. Cancer 2015, 51, $2191-2205$. [CrossRef] [PubMed] 
3. Guzzinati, S.; Virdone, S.; De Angelis, R.; Panato, C.; Buzzoni, C.; Capocaccia, R.; Francisci, S.; Gigli, A.; Zorzi, M.; Tagliabue, G.; et al. Characteristics of people living in Italy after a cancer diagnosis in 2010 and projections to 2020. BMC Cancer 2018, 18, 169. [CrossRef] [PubMed]

4. De Cicco, P.; Catani, M.V.; Gasperi, V.; Sibilano, M.; Quaglietta, M.; Savini, I. Nutrition and breast cancer: A literature review on prevention, treatment and recurrence. Nutrients 2019, 11, 1514. [CrossRef] [PubMed]

5. McEligot, A.J.; Largent, J.; Ziogas, A.; Peel, D.; Anton-Culver, H. Dietary fat, fiber, vegetable, and micronutrients are associated with overall survival in postmenopausal women diagnosed with breast cancer. Nutr. Cancer 2006, 55, 132-140. [CrossRef]

6. Jayedi, A.; Emadi, A.; Khan, T.A.; Abdolshahi, A.; Shab-Bidar, S. Dietary fiber and survival in women with breast cancer: A dose-response meta-analysis of prospective cohort studies. Nutr. Cancer 2020. [CrossRef] [PubMed]

7. He, J.; Gu, Y.; Zhang, S. Vitamin A and breast cancer survival: A systemic review and meta-analysis. Clin. Breast Cancer 2018, 18, e1389-e1400. [CrossRef]

8. Holmes, M.D.; Wang, J.; Hankinson, S.E.; Tamimi, R.M.; Chen, W.Y. Protein intake and breast cancer survival in the Nurses' Health Study. J. Clin. Oncol. 2017, 35, 325-333. [CrossRef]

9. Chlebowski, R.T.; Aragaki, A.K.; Anderson, G.L.; Simon, M.S.; Manson, J.; Neuhouser, M.L.; Pan, K.; Stefanick, M.L.; Rohan, T.E.; Lane, D.; et al. Association of low-fat dietary pattern with breast cancer overall survival. A secondary analysis of the Women's Health Initiative randomized clinical trial. JAMA Oncol. 2018, 4, e181212. [CrossRef] [PubMed]

10. Jochems, S.H.J.; Van Osch, F.H.M.; Bryan, R.T.; Wesselius, A.; van Schooten, F.J.; Cheng, K.K.; Zeegers, M.P. Impact of dietary patterns and the main food groups on mortality and recurrence in cancer survivors: A systemic review of current epidemiological literature. BMI Open 2017, 8, e014530. [CrossRef] [PubMed]

11. Terranova, C.O.; Protani, M.M.; Reeves, M.M. Overall dietary intake and prognosis after breast cancer: A systemic review. Nutr. Cancer 2018, 70, 156-163. [CrossRef] [PubMed]

12. Mazzocchi, A.; Leone, L.; Agostoni, C.; Pali-Schöll, I. The secrets of Mediterranean diet. Does [only] olive oil matter? Nutrients 2019, 11, 2941. [CrossRef] [PubMed]

13. Eleftheriou, D.; Benetou, V.; Trichopoulou, A.; La Vecchia, C.; Bamia, C. Mediterranean diet and its components in relation to all-cause mortality: Meta-analysis. Br. J. Nutr. 2018, 120, 1081-1097. [CrossRef] [PubMed]

14. Morze, J.; Danielewicz, A.; Przybyłowicz, K.; Zeng, H.; Hoffmann, G.; Schwingshackl, L. An updated systemic review and meta-analysis on adherence to Mediterranean diet and risk of cancer. Eur. J. Nutr. 2020. [CrossRef] [PubMed]

15. Kim, E.H.J.; Willett, W.C.; Fung, T.; Rosner, B.; Holmes, M.D. Diet quality indices and postmenopausal breast cancer survival. Nutr. Cancer 2011, 63, 381-388. [CrossRef] [PubMed]

16. Franceschi, S.; Favero, A.; Decarli, A.; Negri, E.; La Vecchia, C.; Ferraroni, M.; Russo, A.; Salvini, S.; Amadori, D.; Conti, E.; et al. Intake of macronutrients and risk of breast cancer. Lancet 1996, 347, 155-160. [CrossRef]

17. Dal Maso, L.; Zucchetto, A.; Talamini, R.; Serraino, D.; Stocco, C.F.; Vercelli, M.; Falcini, F.; Franceschi, S. Effect of obesity and other lifestyle factors on mortality in women with breast cancer. Int. J. Cancer 2008, 123, 2188-2194. [CrossRef]

18. Decarli, A.; Franceschi, S.; Ferraroni, M.; Gnagnarella, P.; Parpinel, M.T.; La Vecchia, C.; Negri, E.; Salvini, S.; Falcini, F.; Giacosa, A. Validation of a food-frequency questionnaire to asses dietary intakes in cancer studies in Italy. Results for specific nutrients. Ann. Epidemiol. 1996, 6, 110-118. [CrossRef]

19. Franceschi, S.; Negri, E.; Salvini, S.; Decarli, A.; Ferraroni, M.; Filiberti, R.; Giacosa, A.; Talamini, R.; Nanni, O.; Panarello, G.; et al. Reproducibility of an Italian food frequency questionnaire for cancer studies. Results for food items. Eur. J. Cancer 1993, 29, 2298-2305. [CrossRef]

20. Gnagnarella, P.; Parpinel, M.; Salvini, S.; Franceschi, S.; Palli, D.; Boyle, P. The update of the Italian Food Composition Database. J. Food Comp. Anal. 2004, 17, 509-522. [CrossRef]

21. Trichopoulou, A.; Costacou, T.; Bamia, C.; Trichopoulos, D. Adherence to a Mediterranean diet and survival in a Greek population. N. Engl. J. Med. 2003, 348, 2599-2608. [CrossRef] [PubMed]

22. Kalbfleisch, J.D.; Prentice, R.L. The Statistical Analysis of Failure Time Data; Wiley: New York, NY, USA, 2002.

23. Fine, J.P.; Gray, R.J. A proportional hazard model for the subdistribution of a competing risk. J. Am. Stat. Assoc. 1999, 94, 496-509. [CrossRef]

24. Gray, R.J. A class of K-sample tests for comparing the cumulative incidence of a competing risk. Ann. Stat. 1988, 161, 1141-1154. [CrossRef] 
25. Dinu, M.; Pagliai, G.; Casini, A.; Sofi, F. Mediterranean diet and multiple health outcomes: An umbrella review of meta-analyses of observational studies and randomised trials. Eur. J. Clin. Nutr. 2018, 72, 30-43. [CrossRef] [PubMed]

26. Kenfield, S.A.; DuPre, N.; Richman, E.L.; Stampfer, M.J.; Chan, JM.; Giovannucci, E.L. Mediterranean diet and prostate cancer risk and mortality in the Health Professionals Follow-up Study. Eur. Urol. 2014, 65, 887-894. [CrossRef] [PubMed]

27. Ratjen, I.; Schafmayer, C.; di Giuseppe, R.; Waniek, S.; Plachta-Danielzik, S.; Koch, M.; Nöthlings, U.; Hampe, J.; Schlesinger, S.; Lieb, W. Postdiagnostic Mediterranean and Healthy Nordic dietary pattern are inversely associated with all-cause mortality in long-term colorectal cancer survivors. J. Nutr. 2017, 147, 636-644. [CrossRef] [PubMed]

28. Howlader, N.; Cronin, K.A.; Kurian, A.W.; Andridge, R. Differences in breast cancer survival by molecular subtypes in the United Staes. Cancer Epidemiol. Biomark. Prev. 2018, 27, 619-626. [CrossRef]

29. Kastorini, C.M.; Milionis, H.J.; Esposito, K.; Giugliano, D.; Goudevenos, J.A.; Panagiotakos, D.B. The effect of Mediterranean diet on metabolic syndrome and its components: A meta-analysis of 50 studies and 534,906 individuals. J. Am. Coll. Cardiol. 2011, 57, 1299-1313. [CrossRef]

30. Kwon, Y.J.; Cho, Y.E.; Cho, A.R.; Choi, W.J.; Yun, S.; Park, H.; Kim, H.S.; Cashion, A.K.; Gill, J.; Lee, H.; et al. The possible influence of Mediterranean diet on extracellular vescicle miRNA expression in breast cancer survival. Cancers 2020, 12, 1355. [CrossRef]

31. Affret, A.; His, M.; Severi, G.; Mancini, F.R.; Arveux, P.; Clavel-Chapelon, F.; Boutron-Ruault, M.C.; Fagherazzi, G. Influence of cancer diagnosis on changes in fruit and vegetable consumption according to cancer site, stage at diagnosis and sociodemographic factors: Results from the large E3N-EPIC study. Int. J. Cancer 2018, 143, 1678-1687. [CrossRef]

32. World Cancer Research Fund International/American Institute for Cancer Research. Diet, Nutrition, Physical Activity, and Breast Cancer Survivors. Continuous Update Project Expert Report 2018. Available online: https://www.wcrf.org/dietandcancer (accessed on 26 August 2020).

Publisher's Note: MDPI stays neutral with regard to jurisdictional claims in published maps and institutional affiliations.

(C) 2020 by the authors. Licensee MDPI, Basel, Switzerland. This article is an open access article distributed under the terms and conditions of the Creative Commons Attribution (CC BY) license (http://creativecommons.org/licenses/by/4.0/). 